\title{
Levels of matrix metalloproteinases differ in plasma and serum - aspects regarding analysis of biological markers in cancer
}

\author{
Andreas Jonsson ${ }^{1,2}$, Claes Hjalmarsson ${ }^{3}$, Peter Falk ${ }^{2}$ and Marie-Lois Ivarsson ${ }^{\star, 1,2}$ \\ ${ }^{1}$ Hallands Hospital Varberg, Region Halland, SE-432 37 Varberg, Sweden; ${ }^{2}$ Fibrinolysis Laboratory, Department of Surgery, \\ Institute of Clinical Sciences, Sahlgrenska Academy at the University of Gothenburg, SE-416 85, Göteborg, Sweden and \\ ${ }^{3}$ Department of Surgery, Kalmar Hospital, SE-391 26 Kalmar, Sweden
}

Background: There are inconsistencies in the use of serum or plasma when analysing the matrix metalloproteinases (MMPs) as diagnostic or prognostic markers. The purpose of this study was to compare the concentration of MMP-1, $-2,-7,-8,-9$ and -13 in serum vs plasma samples.

Methods: Blood samples were obtained from sixty-five men and women. Samples were analysed for levels of MMPs in corresponding citrate plasma and serum.

Results: All MMPs expressed higher concentration in serum compared with plasma $(P<0.01)$. There were no differences between genders.

Conclusions: Present study demonstrated significant differences regarding concentrations of some MMPs using plasma vs serum. We conclude that future studies regarding MMPs as biological markers in cancer should consider the use of citrate plasma instead of serum.

Matrix metalloproteinases (MMPs) are proteases that have a major role in the degradation of the extracellular matrix (Langenskiold et al, 2005). MMPs can be synthesised not only by the tumour cell, but also from surrounding stromal cells. The activity and expression of MMPs is increased in many types of cancer (Cauwe et al, 2007).

Numerous studies indicate a possible value of MMP concentration in blood samples from patients with colorectal cancer, either as a diagnostic or prognostic marker (Tutton et al, 2003; Maurel et al, 2007; Kushlinskii et al, 2013). There is however a lack of consensus with data pointing at different directions and inconsistencies in using serum or plasma analysing MMPs in patients with colorectal neoplasia (Hurst et al, 2007; Damery et al, 2013). Analysing serum for determination of circulating MMP has previously been criticised (Gerlach et al, 2005). MMPs releases from leucocytes during the clotting process, which makes serum samples time-to-analyse dependent (Zucker and Cao, 2005). As a part of further investigation of the MMPs and their use as a diagnostic and prognostic marker, we have explored differences between plasma and serum levels of MMP. The aim of this study was to compare the concentration of MMP-1, -2, -7, -8, -9 and -13 in serum and plasma samples for each patient in a population suitable for a colon cancer-screening programme.

\section{MATERIALS AND METHODS}

Blood collection and sample preparation. Venous blood samples were collected in a standardised way from 65 (34 males, 31 females), 65-years-old individuals participating in a study regarding colorectal cancer screening. Serum samples were collected in tubes without clot activators; plasma samples were collected in citrate tubes. Serum tubes were stored in room temperature $\left(+20^{\circ} \mathrm{C}\right)$ for $30 \mathrm{~min}$ and then centrifuged at $10000 \mathrm{~g}$ in $20^{\circ} \mathrm{C}$, citrate tubes were centrifuged within $5 \mathrm{~min}$ at $10000 \mathrm{~g}$ in $20^{\circ} \mathrm{C}$.

*Correspondence: Professor M-L Ivarsson; E-mail: marie-lois.ivarsson@regionhalland.se 
Supernatants from both serum and citrate plasma were collected and frozen at $-80^{\circ} \mathrm{C}$ in aliquots until further analysed in batches.

Protein level measurement. In all samples levels of MMP-1, MMP-2, MMP-7, MMP-8, MMP-9 and MMP-13 were analysed with the Luminex xMap multi-assay technology (Bio-Plex 200, BIO-RAD, Sundbyberg, Sweden). The samples were measured simultaneously with Fluorokine MAP (Multi-Analyte Profiling, RnD Systems, Abingdon, UK) assay according to the manufacturer's instructions. For MMP-1, the kit detects pro-, mature and TIMP-1 complex MMP-1, with a lower detection limit of $0.57 \mathrm{pg} \mathrm{ml}^{-1}$ together with an intra assay (CV\%) of 7.8-9.0 and an inter-assay of $15.3-16.2 \%$, respectively. For MMP-2, the kit detects pro- and mature MMP-2, with a lower detection limit of $3.8 \mathrm{pg} \mathrm{ml}^{-1}$, and an intra assay (CV\%) of 7.3-9.3 and an interassay of $10.0-13.3 \%$, respectively. For MMP-7, the kit detects pro-, mature and TIMP-1-complexed MMP-7, with a lower detection limit of $3.9 \mathrm{pg} \mathrm{ml}^{-1}$ together with an intra assay (CV\%) of 5.0-9.0 and an inter-assay of $7.7-11.5 \%$, respectively. For MMP-8, the kit detects pro-, mature and TIMP-1-complexed MMP-8, with a lower detection limit of $7.8 \mathrm{pg} \mathrm{ml}^{-1}$ together with an intra assay (CV\%) of 5.2-7.0 and an inter-assay of 9.6-14.3\%, respectively. For MMP-9, the kit detects pro- and mature MMP-9, with a lower detection limit of $5.7 \mathrm{pg} \mathrm{ml}^{-1}$ together with an intra assay (CV\%) of 3.8-5.8 and an inter-assay of 9.3-11.7\%, respectively. For MMP13, the kit detects pro-, mature and TIMP-1 complexed MMP-13, with a lower detection limit of $36.5 \mathrm{pg} \mathrm{ml}^{-1}$ together with an intra assay (CV\%) of 4.3-5.6 and an inter-assay of $10.7-12.6 \%$, respectively.

All samples were prediluted 11-fold. Each sample was measured in duplicates and protein levels in the samples were calculated using a five parameter logistic (5-PL) standard curve according to the manufacture instructions.

Statistical analysis. The MMP analysis was transformed with the natural logarithm to get normally distributed data; this was possible for MMP-1, MMP-8 and MMP-9. Dependent $t$-test was used to compare means between citrate plasma and serum samples. For data not normally distributed the Wilcoxons-signed rank test was used to compare medians (MMP-2, MMP-7). The MannWhitney $U$ test was used to test for differences between genders in the non-normally distributed data, and the independent $t$-test was used for normally distributed data. Correlation between serum and plasma levels was estimated using the Spearman-rank correlation test. All test were two-sided. $P<0.05$ was considered significant. All calculations were carried out with IBM SPSS Statistics for Macintosh (Ver. 22.0, IBM Corp, Armonk, NY, USA).

Ethics. Informed consent was obtained from all participating patients. The study has approval from the Local Ethics Committee at Lund University Hospital, Lund, Sweden.

\section{RESULTS}

In all assays the median levels of the different MMPs found in serum generated a higher value than corresponding levels in citrated plasma $(P<0.01)$. Median and ranges for each assay are reported in detail in Table 1. Levels of MMP-13 were not presented due to concentrations below the detection level.

When comparing the distribution of MMP levels it was found that the interquartile ranges (IQR) were all greater in the serum samples compared to parallel citrated plasma samples (Table 1, Figure 1). There were no significant differences between male or female patients $(P \geqslant 0.05)$ in any of the groups investigated (MMP-1, -2, -7, -8 and -9).

We found a strong positive correlation between serum and plasma samples in the MMP-2 and MMP-7 groups $(P<0.01)$.
Table 1. Medians and interquartile ranges of MMP levels in citrate plasma vs serum $(n=65)$

\begin{tabular}{|c|c|c|c|}
\hline & Citrate plasma & Serum & $P$-value \\
\hline MMP-1 ng ml-1 (IQR) & $0.725(0.921)$ & $5.70(6.50)$ & $<0.01$ \\
\hline MMP-2 $\mathrm{ng} \mathrm{ml}^{-1}$ (IQR) & 288 (216) & $340(252)$ & $<0.01$ \\
\hline MMP-7 ng ml-1 (IQR) & $2.45(2.31)$ & $3.56(2.66)$ & $<0.01$ \\
\hline MMP-8 $\mathrm{ng} \mathrm{ml}^{-1}$ (IQR) & $1.82(4.06)$ & $8.47(13.5)$ & $<0.01$ \\
\hline MMP-9 $\mathrm{ng} \mathrm{ml}^{-1}$ (IQR) & $48.2(64.7)$ & $270(254)$ & $<0.01$ \\
\hline
\end{tabular}

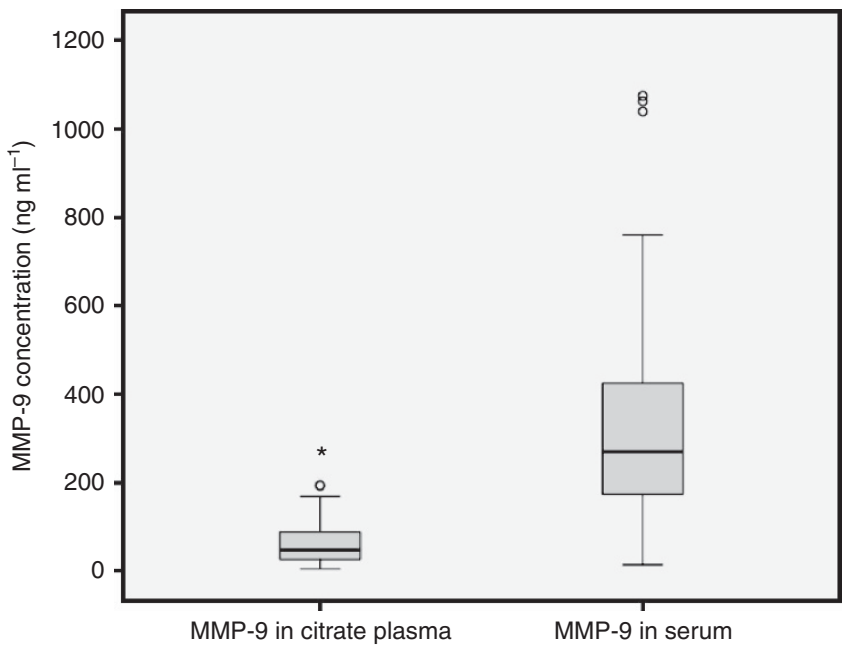

Figure 1. MMP-9 in citrate plasma and serum. Significant higher levels were found in serum. Boxes represent lower and upper quartile and median. Whiskers represent min and max values. Outliers and extreme outliers indicated by $o$ and *, respectively.

Table 2. Correlation coefficient between citrate plasma and serum samples

\begin{tabular}{|l|c|c|}
\hline & Spearman's rho & $\boldsymbol{P}$-value \\
\hline MMP-1 & 0.299 & 0.02 \\
\hline MMP-2 & 0.844 & $<0.01$ \\
\hline MMP-7 & 0.920 & $<0.01$ \\
\hline MMP-8 & 0.225 & 0.07 \\
\hline MMP-9 & 0.150 & 0.20 \\
\hline
\end{tabular}

Despite significance, there was a weak correlation for MMP-1 $(P=0.02)$. The Spearman rank-order correlations for MMP-8 and MMP-9 were not significant $(P>0.05)$, see Table 2 . The IQR were all greater in the serum group compared to the citrate plasma group.

\section{DISCUSSION}

During standardised sampling conditions, we have analysed a larger sample size comparing several MMPs in plasma and serum, which to our knowledge not have been done before (Alby et al, 2002; Gerlach et al, 2005; Jung et al, 2008). We found that the concentration of MMP-1, 2, 7, 8, 9 was significantly higher in serum compared to plasma. There was a strong positive correlation between plasma and serum samples regarding MMP-2 and 
MMP-7. Rather surprisingly, there was no correlation between plasma and serum samples for MMP-8 and MMP-9. Even though, a $P<0.05$ for MMP-1, the linear correlation was negligible. There are contradictory results from earlier studies showing a positive correlation (Gerlach et al, 2009).

The present material consists of 65-year-old individuals $(n=65)$. It is previously shown that plasma levels of MMP-2 and MMP-7 increase with patient age, whereas MMP-9 seems to decrease according to age. Earlier publications have also reported a significant difference in plasma levels of MMP-9 between gender (Kusnierova et al, 2015). However, we did not see a significant difference between gender in either plasma nor serum groups. There are a number of studies performed comparing plasma and serum levels of, above all, MMP-9. However, those studies are either small or analyse just a few different MMPs (Jung et al, 2008; Jung, 2008). MMP-9 has shown to be 10 -fold higher in serum than in plasma sample, it also differs between serum samples collected with or without clotting activator (Jung et al, 2006). In our material, we did not get a 10 -fold increase between plasma and serum samples. This might be due to a quite short time between venous sampling and centrifugation (30 min). At least serum level of MMP-9 is known to increase as storage time between venous sampling and centrifugation increases (Jung et al, 2005), whereas others find no such difference (Gerlach et al, 2007). There are sometimes differences between plasma and serum samples due to the large amount of MMP contained in the platelets, neutrophils and the white blood cells. Those MMPs may be released from the blood cells throughout aggregation (Kalvegren et al, 2011). Concerning our results for MMP-2, the difference between plasma and serum levels is significant, but the difference is far from the magnitude as of MMP-9. This might depend on MMP-2 not being that affected by aggregation (Mannello and Tonti, 2007). There are earlier studies not showing any difference between MMP-2 (Gerlach et al, 2005, 2007) and MMP-8 in serum vs citrate plasma samples (Jung et al, 2008). Deviations from previously presented data could at least partly relate to smaller studies than ours or assays using different technology (Gerlach et al, 2007).

$W u$ et al found that MMP-9 in plasma is significantly higher for patients with gastric cancer compared to a control group with no signs of gastric cancer. However, the serum levels of MMP-9 measured in the same group of patients did not show any correlation with gastric cancer, making serum samples non trustworthy (Wu et al, 2007). Moreover, Fontana et al describe contra dictionary results from a review on MMP levels before and after different hypertension treatments in either serum or plasma samples. However, no study did compare the outcome of both the plasma and serum levels (Fontana et al, 2012), as in the present study.

In summary, the present study demonstrated higher levels of MMPs in serum samples compared to corresponding plasma samples. Moreover, the distributions of levels in the term of IQR were greater for the investigated MMPs in the serum group compared to the plasma/citrate group. The reason for this is not fully understood but it is fair to assume that measurements in serum reflects release of proteases by involved blood cells during the clotting process in the serum tube, but the use of an anticoagulant in the collected blood prevent this artefact (Zucker et al, 1999). This might be an important finding as there are previous publications describing the use of MMPs in both plasma and serum as prognostic or diagnostic predictive biomarkers in systemic blood samples. Still, many of the manuscripts will be published on measurements of MMPs in serum samples when trying to detect tumour diseases. Thus, some of these studies might be repeated using plasma specimen collection instead of serum. We suggest that plasma would be the sample of choice for further studies of MMPs.

\section{ACKNOWLEDGEMENTS}

The study was funded from the Swedish LUA/ALF foundation, Sahlgrenska University Hospital (ALFGBG-143521), from the Swedish Cancer Society (Ref No: 130355), the Inga-Britt and Arne Lundberg Foundation (388/11) and from the Scientific Advisory Board, Halland Region, Sweden.

\section{CONFLICT OF INTEREST}

The authors declare no conflict of interest.

\section{REFERENCES}

Alby C, Ben Abdesselam O, Foglietti MJ, Beaudeux JL (2002) Preanalytical aspects regarding the measurement of metalloproteinase- 9 and tissue inhibitor or metalloproteinase-1 in blood. Clin Chim Acta 325: 183-186. Cauwe B, Van Den Steen PE, Opdenakker G (2007) The biochemical, biological, and pathological kaleidoscope of cell surface substrates processed by matrix metalloproteinases. Crit Rev Biochem Mol Biol 42: $113-185$.

Damery S, Nichols L, Holder R, Ward ST, Warmington S, Wilson S, Wakelam MJ, James J, Ismail T (2013) Assessing the value of matrix metalloproteinase 9 (MMP9) in improving the appropriateness of referrals for colorectal cancer. Br J Cancer 108: 1149-1156.

Fontana V, Silva PS, Gerlach RF, Tanus-Santos JE (2012) Circulating matrix metalloproteinases and their inhibitors in hypertension. Clin Chim Acta 413: 656-662.

Gerlach RF, Demacq C, Jung K, Tanus-Santos JE (2007) Rapid separation of serum does not avoid artificially higher matrix metalloproteinase (MMP)9 levels in serum versus plasma. Clin Biochem 40: 119-123.

Gerlach RF, Meschiari CA, Marcaccini AM, Palei AC, Sandrim VC, Cavalli RC, Tanus-Santos JE (2009) Positive correlations between serum and plasma matrix metalloproteinase (MMP)-2 or MMP-9 levels in disease conditions. Clin Chem Lab Med 47: 888-891.

Gerlach RF, Uzuelli JA, Souza-Tarla CD, Tanus-Santos JE (2005) Effect of anticoagulants on the determination of plasma matrix metalloproteinase (MMP)-2 and MMP-9 activities. Anal Biochem 344: 147-149.

Hurst NG, Stocken DD, Wilson S, Keh C, Wakelam MJ, Ismail T (2007) Elevated serum matrix metalloproteinase 9 (MMP-9) concentration predicts the presence of colorectal neoplasia in symptomatic patients. Br J Cancer 97: 971-977.

Jung K (2008) Is serum matrix metalloproteinase 9 a useful biomarker in detection of colorectal cancer? Considering pre-analytical interference that may influence diagnostic accuracy. Br J Cancer 99: 553-554.

Jung K, Gerlach RF, Tanus-Santos JE (2006) Preanalytical pitfalls of blood sampling to measure true circulating matrix metalloproteinase 9 and tissue inhibitors of matrix metalloproteinases. Clin Chim Acta 373: 180-181.

Jung K, Klotzek S, Stephan C, Mannello F, Lein M (2008) Impact of blood sampling on the circulating matrix metalloproteinases $1,2,3,7,8$, and 9 . Clin Chem 54: 772-773.

Jung K, Meisser A, Bischof P (2005) Blood sampling as critical preanalytical determinant to use circulating MMP and TIMP as surrogate markers for pathological processes. Int J Cancer 116: 1000-1001.

Kalvegren H, Jonsson S, Jonasson L (2011) Release of matrix metalloproteinases-1 and -2 , but not -9 , from activated platelets measured by enzyme-linked immunosorbent assay. Platelets 22: 572-578.

Kushlinskii NE, Gershtein ES, Korotkova EA, Prorokov VV (2013) Prognostic role of tumor-associated proteases in colorectal cancer. Bull Exp Biol Med 154: 365-369.

Kusnierova P, Vsiansky F, Pleva L, Plevova P, Safarcik K, Svagera Z (2015) Reference intervals of plasma matrix metalloproteinases 2, 3, and 9 and serum asymmetric dimethylarginine levels. Scand J Clin Lab Invest 75: 508-513.

Langenskiold M, Holmdahl L, Falk P, Ivarsson ML (2005) Increased plasma MMP-2 protein expression in lymph node-positive patients with colorectal cancer. Int J Colorectal Dis 20: 245-252.

Mannello F, Tonti GA (2007) Gelatinase concentrations and zymographic profiles in human breast cancer: matrix metalloproteinases circulating in 
plasma are better markers for the subclassification and early prediction of cancer: the coagulation/fibrinolysis pathways alter the release,

activation and recovery of different gelatinases in serum. Int J Cancer 121: 216-218.

Maurel J, Nadal C, Garcia-Albeniz X, Gallego R, Carcereny E, Almendro V, Marmol M, Gallardo E, Maria AUGE J, Longaron R, Martinez-Fernandez A, Molina R, Castells A, Gascon P (2007) Serum matrix metalloproteinase 7 levels identifies poor prognosis advanced colorectal cancer patients. Int $J$ Cancer 121: 1066-1071.

Tutton MG, George ML, Eccles SA, Burton S, Swift RI, Abulafi AM (2003) Use of plasma MMP-2 and MMP-9 levels as a surrogate for tumour expression in colorectal cancer patients. Int J Cancer 107: 541-550.
Wu C-Y, Wu M-S, Chiang E-P, Chen Y-J, Chen C-J, Chi N-H, Shih Y-T, Chen G-H, Lin J-T (2007) Plasma matrix metalloproteinase-9 level is better than serum matrix metalloproteinase-9 level to predict gastric cancer evolution. Clin Cancer Res 13: 2054-2060.

Zucker S, Cao J (2005) Measurement of matrix metalloproteinases in serum of patients with melanoma: snarled in technical pitfalls. Clin Cancer Res 11: 5069-5070.

Zucker S, Hymowitz M, Conner C, Zarrabi HM, Hurewitz AN, Matrisian L, Boyd D, Nicolson G, Montana S (1999) Measurement of matrix metalloproteinases and tissue inhibitors of metalloproteinases in blood and tissues. Clinical and experimental applications. Ann N Y Acad Sci 878: 212-227. 